\title{
Ethanol during adolescence decreased the BDNF levels in the hippocampus in adult male Wistar rats, but did not alter aggressive and anxiety-like behaviors
}

\author{
O etanol durante a adolescência reduziu os níveis de BDNF no hipocampo de \\ ratos Wistar machos adultos, mas não alterou os comportamentos agressivos e \\ a ansiedade
}

\begin{abstract}
Letícia Scheidt, ${ }^{1}$ Gabriel Rodrigo Fries, ${ }^{2}$ Laura Stertz, ${ }^{2}$ João Carlos Centurion Cabral, ${ }^{1}$ Flávio Kapczinski, ${ }^{2}$
\end{abstract} Rosa Maria Martins de Almeida ${ }^{1}$

\begin{abstract}
Objective: To investigate the effects of ethanol exposure in adolescent rats during adulthood by assesssing aggression and anxiety-like behaviors and measuring the levels of inflammatory markers.

Methods: Groups of male Wistar rats (mean weight $81.4 \mathrm{~g}, \mathrm{n}=$ 36) were housed in groups of four until postnatal day (PND) 60. From PNDs 30 to 46 , rats received one of three treatments: $3 \mathrm{~g} / \mathrm{kg}$ of ethanol $(15 \% \mathrm{w} / \mathrm{v}$, orally, $\mathrm{n}=16), 1.5 \mathrm{~g} / \mathrm{kg}$ of ethanol $(12.5 \%$ $w / v, P O, n=12)$, or water $(n=12)$ every 48 hours. Animals were assessed for aggressive behavior (resident $\mathrm{x}$ intruder test) and anxiety-like behaviors (elevated plus maze) during adulthood. Results: Animals that received low doses of alcohol showed reduced levels of brain-derived neurotrophic factor (BDNF) in the hippocampus as compared to the control group. No significant difference was found in prefrontal cortex.

Conclusions: Intermittent exposure to alcohol during adolescence is associated with lower levels of BDNF in the hippocampus, probably due the episodic administration of alcohol, but alcohol use did not alter the level agression toward a male intruder or anxiety-like behaviors during the adult phase.
\end{abstract}

Keywords: Adolescence, alcohol abuse, aggression, anxiety, brain-derived neurotrophic factor.

\section{Resumo}

Objetivo: Investigar os efeitos da exposição ao etanol em ratos adolescentes durante a idade adulta sobre os comportamentos agressivos e semelhantes à ansiedade, bem como sobre as medidas de níveis de marcadores inflamatórios.

Métodos: Os grupos de ratos Wistar machos (peso médio de 81,4 $\mathrm{g} ; \mathrm{n}=36$ ) foram alojados em grupos de quatro até o dia pós-natal (DPN) 60. Entre os DPNs 30 e 46, os ratos receberam um dos três tratamentos: $3 \mathrm{~g} / \mathrm{kg}$ de etanol ( $15 \% \mathrm{w} / \mathrm{v}$, oralmente, $\mathrm{n}=16), 1.5$ $\mathrm{g} / \mathrm{kg}$ de etanol $(12,5 \% \mathrm{w} / \mathrm{v}$, oralmente, $\mathrm{n}=12)$, ou água $(\mathrm{n}=12)$ a cada 48 horas. Os comportamentos agressivos (teste residente-intruso) e semelhantes à ansiedade (labirinto em cruz elevado) foram avaliados durante a idade adulta dos animais.

Resultados: Os animais que receberam doses menores de álcool mostraram níveis reduzidos de fator neurotrófico derivado do cérebro (BDNF) no hipocampo quando comparados ao grupo controle. Nenhuma diferença significativa foi verificada no córtex pré-frontal. Conclusões: A exposição intermitente ao álcool durante a adolescência é associada com menores níveis de BDNF no hipocampo, provavelmente divido a administração episódica de álcool, mas o uso não alterou o nível de agressão contra o macho intruso ou os comportamentos semelhantes à ansiedade durante a fase adulta. Descritores: Adolescência, abuso de álcool, agressão, ansiedade, fator neurotrófico derivado do cérebro.

\footnotetext{
${ }^{1}$ Institute of Psychology, Universidade Federal do Rio Grande do Sul (UFRGS), Porto Alegre, RS, Brazil. Laboratory of Experimental Psychology, Neurosciences, and Behavior (LPNeC), UFRGS, Porto Alegre, RS, Brazil. ${ }^{2}$ Molecular Psychiatry Laboratory, National Institute for Translational Medicine, Hospital de Clínicas de Porto Alegre (HCPA), UFRGS, Porto Alegre, RS, Brazil.

Financial support: Conselho Nacional de Desenvolvimento Científico e Tecnológico (CNPq). Gabriel Rodrigo Fries, Flávio Kapczinski, and Rosa Maria Martins de Almeida are CNPq research fellows. Letícia Scheidt, Laura Stertz, and João Carlos Centurion Cabral are graduate scholarship recipients from CNPq or Coordenação de Aperfeiçoamento de Pessoal de Nível Superior (CAPES).

Submitted Mar 25 2015, accepted for publication Jul 21 2015. No conflicts of interest declared concerning the publication of this article.

Suggested citation: Scheidt L, Fries GR, Stertz L, Cabral JC, Kapczinski F, de Almeida RM. Ethanol during adolescence decreased the BDNF levels in the hippocampus in adult male Wistar rats, but did not alter aggressive and anxiety-like behaviors. Trends Psychiatry Psychother. $2015 ; 37(3): 143-151$. http://dx.doi.org/10.1590/2237-6089-2015-0017
} 


\section{Introduction}

Adolescence is usually considered to extend from 12 to 20 or 25 years of age in humans and to cover the period of 28 to 42 postnatal days (PND) in rats. ${ }^{1}$ This phase can be characterized in terms of a behavioral tendency to higher levels of risk exposure, increased exploratory behavior, novelty and seeking sensation, social interaction, and high motor activity. ${ }^{2}$ These features are evolutionarily important to promote maturation and independence skills for adulthood, and in different species. Mice are at 21 days of age when they are able to avoid predators, locate food sources, and establish a domestic territory. ${ }^{3}$

The adolescent brain undergoes a transition, including its maturation and changes in a variety of systems, from the molecular composition and sensitivity of receptors to neurotransmitters to more global changes in the volume of the prefrontal cortex (PFC), declining during adolescence both in humans and in rats. There are also changes in the number of synapses, the levels of dopaminergic and cholinergic innervation, as well as modifications in a variety of brain regions. ${ }^{4}$ Therefore, the adolescent brain is different from the adult, and adolescents also differ in their response to ethanol. Adolescent rats are less sensitive to the sedative effects of ethanol, with a rapid and acute tolerance. ${ }^{5}$

Brain damage induced by binge drinking leads to the development of tolerance and dependence that later on promotes overconsumption, but is also associated with changes in brain physiology, structure and function. ${ }^{6}$ In animal models, damages appear to be greater in adolescent than in adult brains, particularly in learning and memory processes. ${ }^{2}$

There is recognized importance of hippocampal neurogenesis in learning and memory as well as in affective and mood states. One study indicated that adolescents present higher levels of neurogenesis in the hippocampus, which is also very sensitive to alcoholinduced inhibition. ${ }^{4}$ Likewise, the consumption of a high number of alcoholic drinks per episode seems to be correlated to a smaller volume of the PFC. Social drinkers who consume alcoholic drinks more heavily were found to have a more negative mood and poorer performance on tasks of executive functions. ${ }^{7}$

Alcohol abuse has dramatic health effects. Cytokine levels have been related to the pathogenesis of numerous disorders, inflammatory diseases, and psychological ilnesses such as mood disorders. ${ }^{8}$ The tumor necrosis factor alpha (TNF-a) is a proinflammatory cytokine, i.e., its increase indicates an inflammation in the body. ${ }^{9}$ Interleukin-10 (IL-10) is an anti-inflammatory cytokine secreted by type
$2 \mathrm{~T}$ helper lymphocytes that regulates the immune system and inhibits allergic reactions. ${ }^{10}$ The cytokine interleukin-1 (IL-1) is a potent defender of the host against infection and damage, both inside and outside the central nervous system (CNS), participating in the maintenance of inflammatory response. ${ }^{11}$

Recognition of the involvement of neuroimmune activation in chronic alcohol exposure-induced damage is relatively recent. ${ }^{12}$ The model of binge drinking shows that alcohol-induced degeneration occurs probably due to inhibition of multiple factors related to cell generation, cellular atrophy, and cell death. Experiments have shown that alcohol alters the balance of pro-inflammatory vs. pro-survival signaling during intoxication. Ethanol promotes the activation of the nuclear transcription factor $\mathrm{kB}$ (NF-kB), as well as increases the levels of pro-inflammatory cytokines and oxidative stress. Ethanol also promotes a reduction in the levels of PCREB (a transcription factor, cAMPresponsive element binding protein), ultimately sensitizing neurons to damage by influencing the loss of neurogenesis. ${ }^{6}$ Human alcoholics present increased levels of brain cytokines and markers of microglia, which are consistent with these processes and therefore contribute to the loss of gray and white matter, as well as to cognitive dysfunction. ${ }^{12}$

Despite the high prevalence of use and abuse of alcohol and related disorders in adolescence, understanding of the effects of consumption at an early age on brain development and cognition is just beginning. Understanding brain responses to ethanol in this age group is important precisely because it is the period in which individuals usually start drinking. ${ }^{13}$ Although there are legal restrictions on the use of alcohol by adolescents, these practices are quite common and largely uncontrolled. ${ }^{14}$

The aims of this study were to investigate the effects of ethanol exposure in adolescent rats and assess aggression and anxiety-like behaviors. Moreover, we also assessed the levels of brain-derived neurotrophic factor (BDNF), IL-1a, IL-10 and TNF-a in PFC and hippocampus during adulthood.

\section{Methods}

This experimental study was conducted to compare experimental groups with different doses of ethanol (E10 and E30) and a control group with regard to aggression and anxiety-like behaviors and inflammatory activity (dependent variables). The study was approved by the Ethics Committee on Animal Use of Universidade Federal do Rio Grande do Sul (UFRGS), Brazil. 
Table 1 - Division of the experimental groups according to the administration of ethanol by gavage

\begin{tabular}{lccc}
\hline & $\begin{array}{c}\text { Control } \\
(\mathbf{n}=\mathbf{1 2})\end{array}$ & $\begin{array}{c}\text { E10 } \\
(\mathbf{n = 1 2})\end{array}$ & $\begin{array}{c}\text { E30 } \\
(\mathbf{n}=\mathbf{1 6})\end{array}$ \\
\hline Substance & Water & Ethanol & Ethanol \\
Concentration & $0 \% \mathrm{w} / \mathrm{v}$ & $5 \% \mathrm{w} / \mathrm{v}$ & $15 \% \mathrm{w} / \mathrm{v}$ \\
Volume & 1 and $2 \mathrm{~mL} /$ & $1 \mathrm{~mL} / 100 \mathrm{~g}$ & $2 \mathrm{~mL} / 100 \mathrm{~g}$ \\
Ethanol (weight) & $100 \mathrm{~g}$ & & \\
\hline
\end{tabular}

\section{Animals}

Forty male Wistar rats aged 21 days were housed in the Animal Research Unit of the Hospital de Clinicas de Porto Alegre (HCPA), under a 12 h light/dark cycle, with controlled ambient temperature (20-22 ${ }^{\circ} \mathrm{C}$ ) and relative humidity (40-60\%). Animals were housed in groups of four rats per cage in polyurethane boxes measuring $24 \mathrm{~cm}$ in width, $38 \mathrm{~cm}$ in length, and 15 $\mathrm{cm}$ in height. After an acclimatization period of 7 days in the vivarium, animals were assigned to treatment groups (E10, E30, and control) (Table 1). All animals weighed between 63 and $96 \mathrm{~g}$ on PND 28 and received chow and drinking water without restriction throughout the experiment.

\section{Procedures}

After the assignment of subjects to groups, an intermittent exposure to ethanol was performed from the PNDs 30 to 46 . The protocol was based on the one proposed by Pascual et al., ${ }^{15}$ however using gavage instead of intraperitoneal injections. Animals received either doses of $15 \%(\mathrm{w} / \mathrm{v}), 3.0 \mathrm{~g} / \mathrm{kg}$ ethanol (95\% EtOH) diluted in water (group E30); 5\% (w/v), 1.0 $\mathrm{g} / \mathrm{kg}$ of ethanol diluted in water (group E10); or just water (control group) every 48 hours, totaling eight administrations per animal. The solution was applied with a gavage. The animals were weighed immediately before each exposure for the accurate calculation of the quantity by weight. This model is intended to simulate a consumption pattern characterized by intermittent use at high doses, common in adolescent binge drinking behavior. ${ }^{15}$ Procedures are shown in Figure 1.

\section{Behavioral tests}

\section{Risk behavior and anxiety}

Risk and anxiety behaviors were assessed using the elevated plus maze (EPM), which consisted of a wooden apparatus with four arms $(50 \times 10 \mathrm{~cm})$, two open and two closed. The sides of the latter are closed by walls measuring $40 \mathrm{~cm}$ in height. The apparatus is elevated 50 $\mathrm{cm}$ from the ground. ${ }^{16,17}$

Animals were tested with the EPM between PNDs 64 and $65 .{ }^{18}$ In a single exposure, the rats were placed individually in the center of the maze facing one of the open arms. The activity of the animal in the maze was examined by the number of entries into the open and closed arms and by the time spent in each arm for a period of 5 minutes. An entry was counted when the animal placed all four paws on one arm. After removal of each rat, the apparatus was cleaned and disinfected prior to testing the next animal. The experiment was recorded with a camera mounted about one meter above the apparatus.

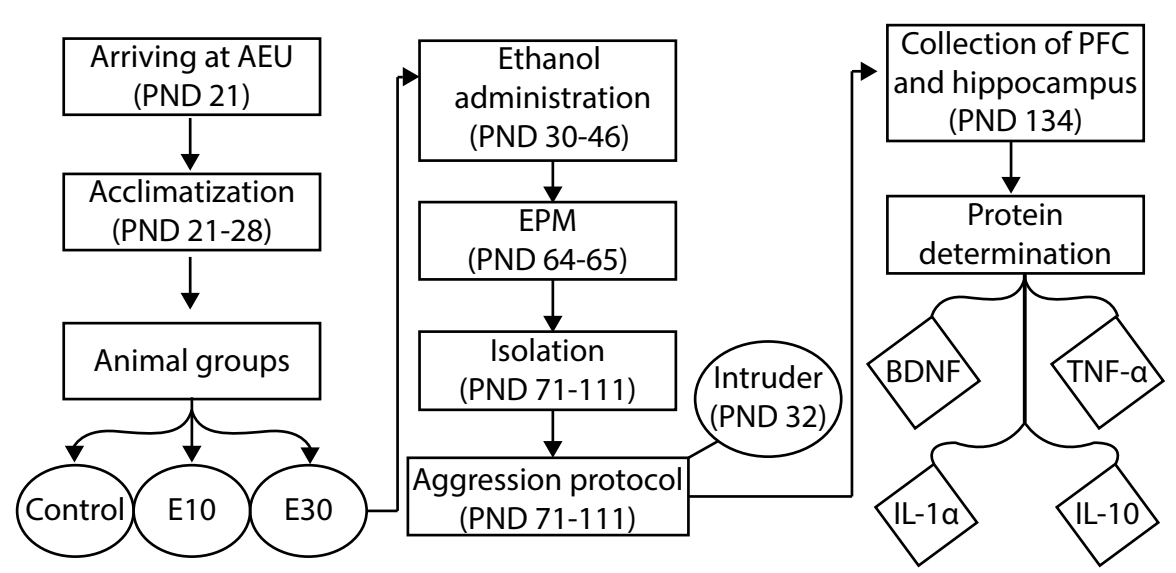

Figure 1 - Flowchart of study procedures, covering the arrival of the animals at the AEU, their acclimatization, their division into three groups, ethanol administration, behavioral tests, and brain analysis. BDNF = brain-derived neurotrophic factor; EPM = elevated plus maze; IL-1a = interleukin 1 alpha; IL-10 = interleukin 10; PFC = prefrontal cortex; PND = postnatal day; TNF- $a=$ tumor necrosis factor alpha; $\mathrm{AEU}=$ animal experimentation unit. 
After training, two observers reviewed videorecordings and analyzed the following behaviors, according to Walf \& Frye, ${ }^{18}$ Toledo-Rodriguez \& Sandi, ${ }^{19}$ and Robert et al. ${ }^{20}$ :

- Behavior of the anxious type: latency, total time and number of entries into the closed arms;

- Behavior of non-anxious type: latency, total time and number of entries into the open arms;

- Risk-taking behavior/risk assessment: latency, frequency and duration of the stretching behavior (when the rodent puts his head out of the closed arm, investigating the environment); latency, frequency and duration of head dips (when the rodent extends his head beyond the limits of the open arm);

- Other: latency, frequency and duration of grooming (self-cleaning behavior), latency, frequency and duration of rearing (when the rodent stands vertically on two hindlegs).

\section{Aggression test}

To perform the assessment of aggressive behavior, animals were placed in individual transparent boxes and visually isolated by partitioning between boxes. The isolation period was between PNDs 71 and 111, totaling 40 days. The isolation is required for the animal to express more aggressive behavior repertoire to interact with intruders. Thirty-five animals of 32 days of age were used as intruders, in confrontation with the residents. These were used alternately, with no resident-intruder pair being repeated throughout the interactions.

The protocol used for the experiment was based on the aggression assessment proposed by Miczek. ${ }^{21}$ On the PND 112, interactions began. An attacker animal, which resided with another group of animals, was placed in the transparent box-dwelling of each rat treated or not with ethanol during adolescence. The experiment was conducted during the dark cycle, twice a week, over four weeks, totalling seven events. Each exposure was recorded with an infrared device installed in front of the box and engraved with Windows Movie Maker. Interactions were held concurrently for four different teams, with four pairs of animals. Intruders were marked throughout the body to facilitate visualization and differentiation of resident crew.

The interaction time was 10 minutes from the first bite by the resident toward the intruder. In the absence of attacks the experiment was terminated 10 minutes after introduction of the animal in the box. If the intruder had bitten the resident only after being attacked, the experiment was performed as normal. However, if the intruder had exhibited biting behavior first, the experiment was stopped immediately.
Subsequently, a trained observer analyzed behaviors shown in the recordings, in addition to two judges who analyzed videos of animals drawn. Latency, frequency and duration of each of the following behaviors were calculated: 1) aggressive elements: bite the intruder (bite attack), sideways threat, side posture submission with two legs (pin), nips, and persecution (pursuits); 2) non-aggressive elements: grooming, walking, standing up (rearing), scanning, and sniffing.

\section{Collection of tissues}

At the end of the aggression protocol, control and experimental animals were sacrificed by decapitation. Brains were immediately dissected on ice and the PFC and hippocampus structures were collected, frozen in isopentane cooled in dry ice, and stored at $-80^{\circ} \mathrm{C}$.

\section{Protein determination}

Determination of cytokines and BDNF was performed at the Laboratory of Molecular Psychiatry, HCPA, UFRGS, Brazil. Levels of cytokines in tissues were measured by cytometric bead array (CBA), using the following kits: BD $^{\mathrm{TM}}$ Rat IL-1a CBA Flex Set, BD $^{\mathrm{TM}}$ Rat CBA Flex Set IL-10, and $B D^{\mathrm{TM}}$ CBA Flex Set Rat Serum TNF (BD Biosciences). Tissues were initially homogenized in 150 $\mu \mathrm{L}$ of buffer, which was followed by centrifugation and storage of the supernatant. Afterward, samples were incubated with capture beads labeled with antibodies specific for the respective cytokines to be measured, followed by the incubation with detection antibodies labeled with phycoerythrin (PE). After incubations, $1 \mathrm{~mL}$ of wash solution (Wash Acquire) was added, samples were centrifuged for 10 minutes at 1,000 rpm, the supernatant was discarded, and the samples were suspended for flow cytometer analysis. The results were generated in graphical and tabular forms using BD CBA FCAP Array Software ${ }^{\mathrm{TM}}$ (BD Biosciences, San Diego, USA). Total protein concentration in the extract was evaluated by the Bradford ${ }^{22}$ method. BDNF levels were measured by a sandwich ELISA kit (Millipore), according to the manufacturer's instructions.

\section{Data analysis}

Comparisons between groups were performed assuming a significance level of 0.05 . The EPM protocol was subjected to analysis of variance (ANOVA) to the percentage and duration of entries into the open arms. Principal component analysis (PCA) was performed to extract five factors related to anxiety and risk behavior, as suggested by Cruz et al. ${ }^{16}$ To consider 
the level of aggressiveness integrating variables, we used the formula described by de Almeida et al. ${ }^{23}$ for the measurement of total aggression: the sum of the frequency of aggressive acts (bites, sideways threats, pin, and nip) plus the duration of aggressive postures (sideways threats and pin). From this measurement, the animals were divided into two groups: very aggressive and less aggressive. In one analysis, we used only data from the last three days of the aggression protocol, because, given the fact that the Wistar species is typically aggressive, the first interactions could be considered training and encouragement to aggressive behavior. These interactions, however, were also taken into account in the analysis of variance for repeated measures to observe the changes in the levels of aggression throughout the seven test trials in residentintruder protocol for each resident animal.

Biochemical data showed non-normal distribution and were transformed using logarithmic function and excluding outliers in order to normalize and thus carry out parametric analysis. Two different formulas were used: $-1 * \log (y)$ for TNF-a and IL-10 that did not fall to negative and Ln (y) for IL-1a. Shapiro-Wilk normality test was used to confirm normality. Subsequently, oneway ANOVA with Dunnett's post-hoc test was performed.

\section{Results}

\section{Anxiety and risk exposure}

To analyze the pattern of anxiety due to EPM, a factor analysis was performed, as proposed Cruz et al.., ${ }^{16}$ with the frequency and duration of each behavior generating five scores. The load of each behavioral parameter provides an estimate of how much the variable reflects a factor; a value of 1.0 indicates perfect reflection, while a load of $<0.4$ indicates poor reflection. The factors extracted from this analysis are independent and reflect different processes, explaining $84.9 \%$ of the variance. Table 2 shows the grouping of variables by factor.

Factor 1 adds variables related to risk exposure (duration and number of entries into open arms, duration and number of head dips). Factor 2 adds variables related to grooming. The third factor relates to stretching behavior (assessing risk). The factor 4 comes to anxious behaviors related to time spent in the closed arms. And the factor 5 groups duration and frequency of rearing).

After normalizing and transforming data, groups were compared by one-way ANOVA, using the factors like anxiety scores from the PCA. No statistically significant difference was found (factor $1, F=1.09, p=0.35$; factor $2, F=1.63, p=0.21$; factor $3, F=0.19, p=0.82$ ).

Based on the work by Cruz et al., ${ }^{16}$ an ANOVA was also performed to assess differences between groups, $E 10$ and $E 30$, regarding the percentage of entries ( $F=$ 2.04, $p=0.14$ ) and the percentage of time spent in the open arms $(F=1.04, p=0.36)$ relative to the total frequency ( $F=0.84, p=0.92$ ), but no statistically significant differences were found. In addition to the frequency and duration, an analysis of variance for the variables of latency to the expression of behavior was performed. Data of entries into closed and open arms ( $F$ $=0.46, \mathrm{p}=0.63$ and $\mathrm{F}=2.38, \mathrm{p}=0.11$ respectively), stretching $(F=1.07, p=0.35)$, head dipping $(F=1.78$, $p=0.18)$, grooming $(F=0.24, p=0.79)$, and rearing $(F=0.98, p=0.38)$ were not statistically significant.

Table 2 - Behavioral factors at the elevated plus maze

\begin{tabular}{|c|c|c|c|c|c|}
\hline Factor & 1 & 2 & 3 & 4 & 5 \\
\hline Duration open arm & 0.968 & & & & \\
\hline Frequency open arm & 0.917 & & & & \\
\hline Frequency head dipping & 0.905 & & & & \\
\hline Duration head dipping & 0.872 & & & & \\
\hline Duration closed arm & -0.622 & 0.452 & & & \\
\hline Duration grooming & & 0.883 & & & \\
\hline Frequency grooming & & 0.876 & & & \\
\hline Duration central square & & -0.563 & 0.534 & & \\
\hline Frequency stretching & & & 0.856 & & \\
\hline Duration stretching & & & 0.839 & & \\
\hline Frequency closed arm & & & & 0.925 & \\
\hline Frequency central square & 0.543 & & & 0.802 & \\
\hline Duration rearing & & & & & 0.923 \\
\hline Frequency rearing & & & & & 0.858 \\
\hline
\end{tabular}


Table 3 - Total aggression scores: sum of frequencies of aggressive acts (bites, sideways threats pin, and nip) plus duration of aggressive postures (sideways threats and pin)

\begin{tabular}{|c|c|c|c|c|c|}
\hline Scores & Control $(n=12)$ & $\operatorname{E10}(n=12)$ & $\operatorname{E30}(n=16)$ & $\mathbf{F}$ & p-value \\
\hline Total aggression & $32.20 \pm 12.40$ & $26.14 \pm 9.92$ & $31.56 \pm 11.81$ & 1.02 & 0.370 \\
\hline Mean of aggression z score & $0.36 \pm 3.54$ & $0.47 \pm 3.24$ & $0.12 \pm 3.03$ & 0.19 & 0.820 \\
\hline Sum of aggression & $96.60 \pm 37.22$ & $78.42 \pm 29.76$ & $94.69 \pm 35.43$ & 1.02 & 0.370 \\
\hline
\end{tabular}

Data expressed as mean \pm standard deviation.

$\mathrm{E} 10=5 \%$ ethanol $\mathrm{w} / \mathrm{v} ; \mathrm{E} 30=15 \%$ ethanol $\mathrm{w} / \mathrm{v}$.

\section{Aggression analysis}

For calculation of aggression, using the formula described - sum of frequencies (bites, sideways threats, pin, and nip) with duration (sideways threats and pin) -only the last three tests of the aggression protocol were considered for each animal. Data for the variables that were not normally distributed were normalized and described in mean \pm standard deviation, with mean standardized score (z score), total sum and sum with $z$ score at Table 3. This difference was not significant.

Based on the level of aggression, animals were divided into two groups: more aggressive and less aggressive for the mean. We analyzed whether any of the groups (E10, E30 or control) was more aggressive, using the chi-square test, but there was no significant difference between the groups.

Subsequently, repeated measures analysis was performed for the seven test trials of each animal, using the formula of aggression in each time. There was no statistical difference in this analysis.

\section{Cytokines and BDNF}

The presence of TNF- $a$ in the PFC showed no significant differences among groups $(F=0.51, p=$ 0.61 ). Mean concentration was $0.61 \pm 0.16 \mathrm{pg} / \mathrm{mg}$ in the control group, $0.58 \pm 0.18 \mathrm{pg} / \mathrm{mg}$ in the E10 group, and $0.66 \pm 0.18 \mathrm{pg} / \mathrm{mg}$ in the $\mathrm{E} 30$ group.

The concentration of TNF- $a$ in the hippocampus showed no significant differences among groups $(F=0.64, p=$ 0.53 ). Mean concentrations were $0.96 \pm 0.16 \mathrm{pg} / \mathrm{mg}$ in the control group, $0.92 \pm 0.21 \mathrm{pg} / \mathrm{mg}$ in the E10 group, and $0.86 \pm 0.27 \mathrm{pg} / \mathrm{mg}$ in the E30 group, as shown in Figure $2 \mathrm{~A}$.

For the IL-10 variable in the PFC, mean concentrations were $1.60 \pm 0.48 \mathrm{pg} / \mathrm{mg}$ for the control group, $1.25 \pm 0.14 \mathrm{pg} / \mathrm{mg}$ for the E10 group, and $1.55 \pm 0.27 \mathrm{pg} / \mathrm{mg}$ for the E30 group. IL-10 levels in the PFC were not significantly different between the groups ( $F=2.92, p=0.07$ ).

The difference in IL-10 concentration in the hippocampus was not statistically significant between the groups ( $F=0.33, p=0.72)$. The mean concentrations found were $1.99 \pm 0.70 \mathrm{pg} / \mathrm{mg}$ for the control group, $1.84 \pm 0.18 \mathrm{pg} / \mathrm{mg}$ for the E10 group, and $1.91 \pm 0.27 \mathrm{pg} /$ $\mathrm{mg}$ for the E30 group, as shown in Figure 2B.

The levels of IL-1a in the PFC showed no significant differences between the groups, $F=3.01$ ( $p=0.06$ ). Mean concentration was $1.58 \pm 0.34 \mathrm{pg} / \mathrm{mg}$ in the control group, $1.89 \pm 0.31 \mathrm{pg} / \mathrm{mg}$ in the E10 group, and $1.65 \pm 0.28 \mathrm{pg} / \mathrm{mg}$ in the E30 group.

The concentration of IL-1a in the hippocampus showed no significant differences among groups ( $\mathrm{F}=$ $2.63, \mathrm{p}=0.09$ ). Mean concentration was $1.59 \pm 0.34$ $\mathrm{pg} / \mathrm{mg}$ in the control group; $1.66 \pm 0.23 \mathrm{pg} / \mathrm{mg}$ in the E10 group; and $1.40 \pm 0.26 \mathrm{pg} / \mathrm{mg}$ in the E30 group, as shown in Figure 2C.

Mean BDNF concentrationin PFC were the following: $0.26 \pm 0.08 \mathrm{pg} / \mathrm{mg}$ in the control group, $0.25 \pm 0.19 \mathrm{pg} /$ $\mathrm{mg}$ in the E10 group, and $0.23 \pm 0.09 \mathrm{pg} / \mathrm{mg}$ in the E30 group. The presence of BDNF in PFC was not significantly different between the groups $(F=0.12, p=0.89)$.

Regarding the presence of BDNF in the hippocampus, a mean of $0.57 \pm 0.19 \mathrm{pg} / \mathrm{mg}$ was found in the control group, $0.38 \pm 0.15 \mathrm{pg} / \mathrm{mg}$ in the E10 group, and $0.54 \pm 0.19 \mathrm{pg} / \mathrm{mg}$ in the E30 group. The concentration of BDNF in hippocampus showed a significant difference among the groups $(F=3.32, p$ $=0.048$ ). The Dunnett post-hoc test showed that this difference was significant between control and E10 groups (mean $=0.19$ ), but not between control and E30 groups (mean $=0.03$ ). Therefore, BDNF levels were significantly higher in the hippocampus of the control group $(0.57 \mathrm{pg} / \mathrm{mg})$ in comparison to the E10 group $(0.38 \mathrm{pg} / \mathrm{mg})$, but not in comparison to the E30 $(0.54 \mathrm{pg} / \mathrm{mg})$, as shown in Figure 2D. 
A

PFC

IL 10

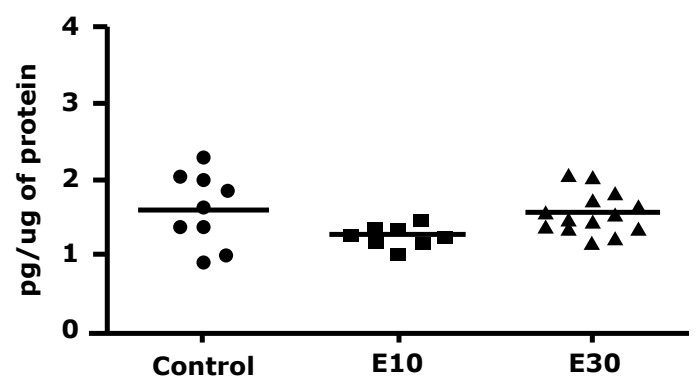

B

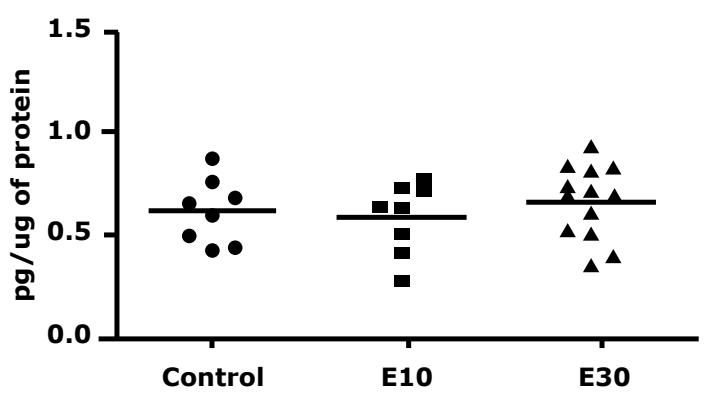

C

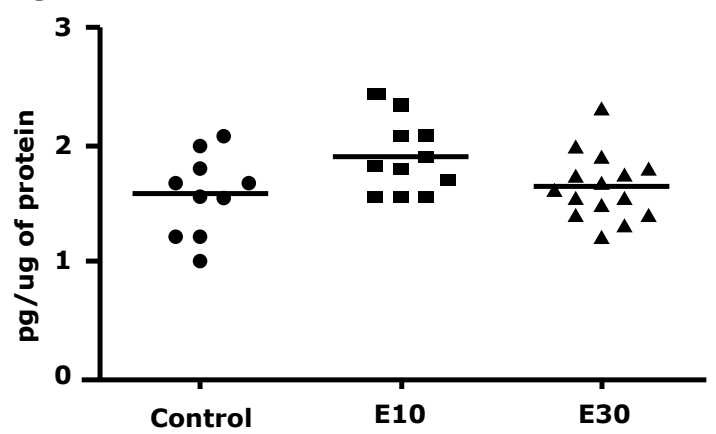

D

BDNF

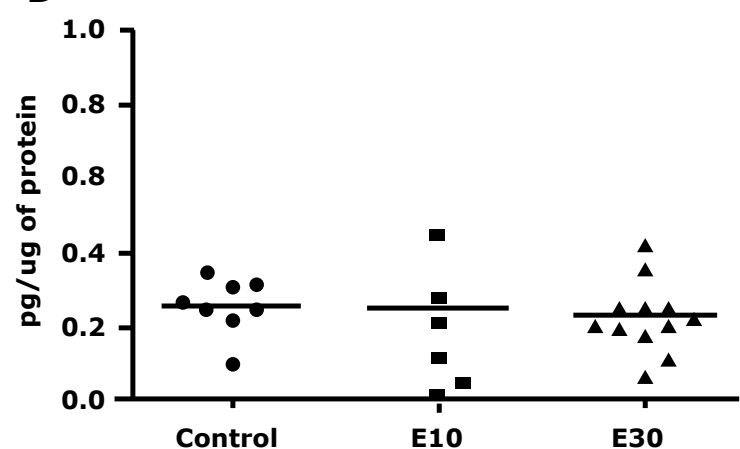

Hippocampus

IL 10

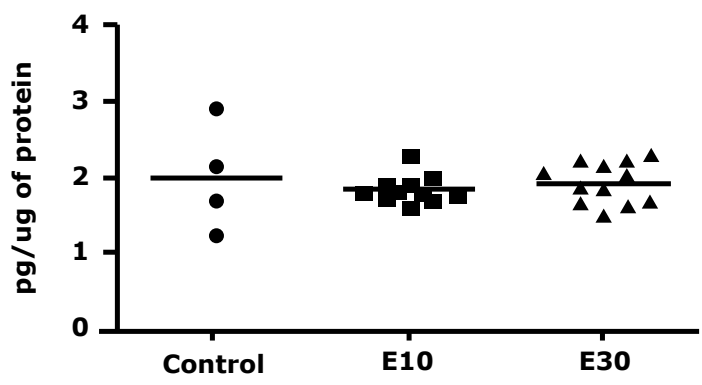

TNF-a

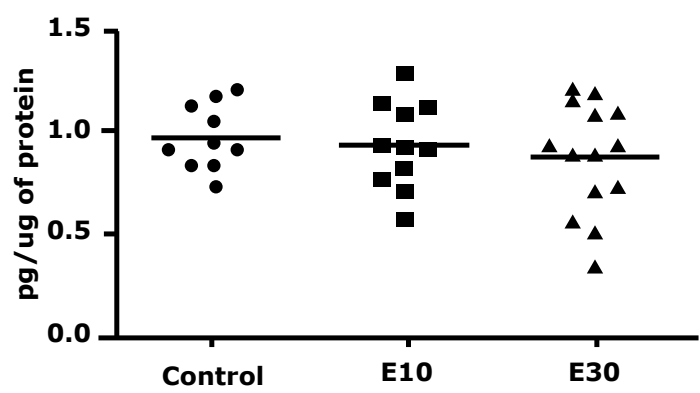

IL -1a

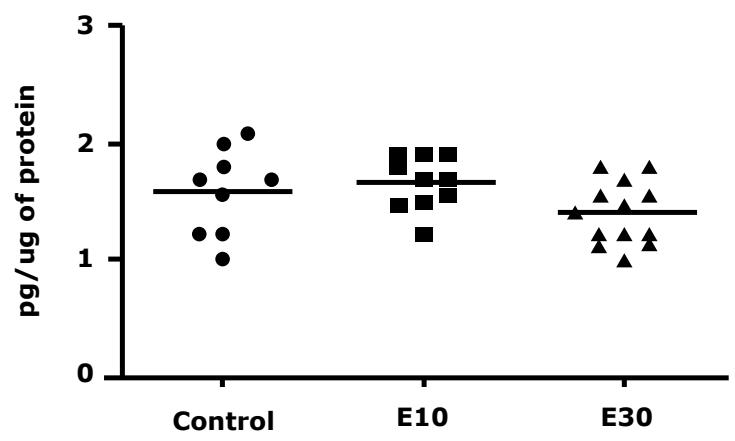

BDNF

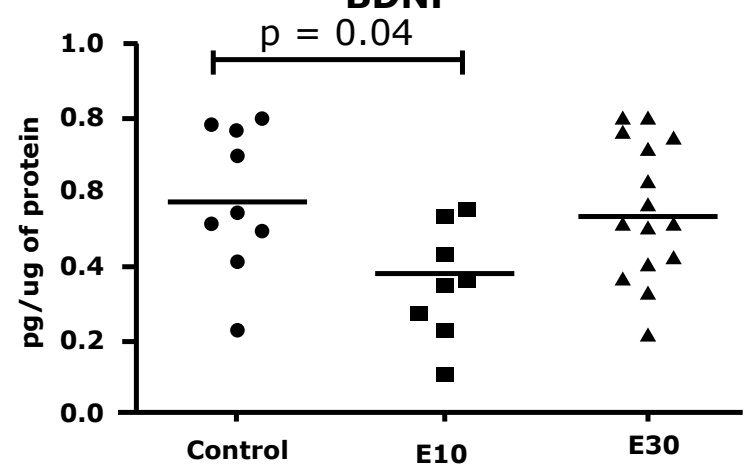

Figure 2 - IL-10, IL-1a and TNF-a levels measured in the PFC and hippocampus from male Wistar rats. $\mathrm{BDNF}=$ brain-derived neurotrophic factor; IL-1a = interleukin-1 alpha; IL10 = interleukin-10; TNF- $a=$ tumor necrosis factor alpha; PFC = prefrontal cortex. 


\section{Discussion}

The present study investigated the relationship between alcohol use in adolescence and aggressive and anxiety-like behaviors and inflammatory activity in the CNS in adulthood. The results indicated that the administration of alcohol by gavage during adolescence lead any behaviroal change regarding risk exposure and anxiety-like behaviors. There was a clear dissociation between the behaviors studied, such as aggression and anxiety-like behaviors, and the neurochemistry markers assessed in this study. Of note, alcohol consumption is age-dependent, such that adults are more sensitive than adolescent rats. ${ }^{24}$

One possible reason for the initial hypothesis not to have been supported by our results is that alcohol was administered at a time in which possibly the drug is not as harmful to the brain areas related to anxiety and risk behavior. Customarely, the age of adolescence in rats is defined as the period between PNDs 28 and 42 . However, our gavage protocol was held between PNDs 30 and 46. In addition, the intervals between doses were one to two days, which may have characterized a low frequency of alcohol intake. The amount of ethanol administered varies for each protocol. Crews \& Nixon ${ }^{6}$ even proposed a model of binge drinking using $9 \mathrm{~g} / \mathrm{kg} /$ day ethanol, although they admit that $5 \mathrm{~g} / \mathrm{kg} /$ day significantly cause poisoning. However, in the present experiment, the choice of $3 \mathrm{~g} / \mathrm{kg}$ for reproduction of binge drinking seemed more appropriate due to the ethical care about the safety of animals, taking the possible hepatotoxicity and other side effects of alcohol into account. It is important to consider, however, that dose used in our study may not have been sufficient to cause prolonged and profound CNS effects.

Another explanation for the lack of statistical significance in the findings is that ethanol administration by gavage instead of intraperitoneal injections ${ }^{15}$ may have generated lower bioavailability ${ }^{25}$ and might therefore have been insufficient to generate physiological changes related to anxious behavior and risk exposure in brain structures such as PFC. ${ }^{26}$

One of the major problems in developing a model of drinking behavior in rodents, according to McBride et al., ${ }^{27}$ is that most rodents do not readily and voluntarily consume ethanol without experimental manipulation. The researchers add that, because of the relatively narrow window of development that characterizes adolescence in animals, it is very difficult to establish the underlying behavior of adolescent drinking and its consequences for long-term mechanisms. In the present study, much time has passed between ethanol administration by gavage and quantification of proteins. One possible explanation for the difference of cytokines in the structures is the presence of intervening variables that could not be controlled in the experiment.

Ethanol is known to induce an immune response in the brain, which may contribute to ethanol-induced neurodegeneration. However, a recent study ${ }^{28}$ that investigated the effects of ethanol in aged mice found that ethanol induced chemokine ( $\mathrm{C}-\mathrm{C}$ motif) ligand 2 selectively in the hippocampus and cerebellum but not in the cerebral cortex. Furthermore, ethanol did not increase IL- 6 or TNF-a expression in any of these brain regions. Indeed, relatively little is known concerning the long-term effects of ethanol on immune activity in the CNS. Moreover, alcohol can increase the immune response in adult more than adolescent CNS. Although several studies have demonstrated the long-term effects of ethanol exposure, mainly prenatal chronic ethanol exposure, ${ }^{29}$ data on the long-term effects of intermittent exposure to alcohol on the adolescent brain are still controversial. Future studies are needed to evaluate the effects of continuous ethanol exposure on different parts of the brain of adult animals treated with ethanol during adolescence.

The most significant finding in this study was the decrease in BDNF concentration in the hippocampus of rats exposed to the intermediate dose of ethanol during adolescence $(1 \mathrm{~g} / \mathrm{kg} ; 2 \mathrm{~mL} / 100 \mathrm{~g}$ ) compared to the control group. It is known that BDNF is a regulator of development, plasticity, and addictive behavior. ${ }^{30}$ The literature points out that ethanol-induced decrease in neurotrophic activity in adult brain may be involved in the etiology of developmental disorders related to alcohol neurodegeneration. ${ }^{31}$ This happens due to a decrease in the BDNF expression or due to the inability of the receiver to translate signals in the presence of ethanol. ${ }^{30}$ Studies have shown that chronic ethanol treatment in rats decreases the expression of BDNF in hippocampus and cortex. ${ }^{32}$

Apart from the behavioral tests, this study also performed biochemical analyzes to assess the levels of proinflammatory (TNF-a) and anti-inflammatory (IL-1a and IL-10) cytokines and BDNF in hippocampus and PFC structures. Although the literature still identifies many gaps and uncertainties about the inflammatory activity in the CNS, ${ }^{30}$ we started with the hypothesis that the highest dose of alcohol would increase the presence of proinflammatory cytokines and lower the levels of antiinflammatory cytokines and BDNF, which would be an indicator of neurogenic activity and neuroplasticity.

Evidence suggests that alcohol use in adolescence is associated with a number of problems, including lower performance on tasks associated with executive functions, changes in brain structures, inflammatory 
processes, and behavioral disorders that are perpetuated in adulthood, such as high levels of anxiety and aggressiveness. ${ }^{33}$ Many mechanisms involved in this process are not well understood and the question remains whether the recovery of brain integrity and cognitive function is easier at an young age, given the greater brain plasticity or, on the contrary, neurotoxicity affects neuromaturational course, making recovery less likely. ${ }^{34}$

The experiment presented here gathered several variables that could interact in the process of ethanolinduced brain damage, thus making important contributions to the study of this area. As noted, however, the protocols were not able to identify significant differences in behavioral changes, but we were able to discuss some likely reasons for these findings. With respect to biochemical activity, the most noteworthy result was the significant decrease of BDNF in the hippocampus of animals receiving the intermediate dose of ethanol, but this difference was not found for the highest dosage.

This study is expected to contribute to new research related to the topic of alcohol use in adolescence, especially binge drinking, to better understand the behavioral and biochemical changes resulting from this habit. Further studies should be conducted with other experimental protocols and the analysis of inflammatory markers and other brain structures.

\section{References}

1. Dahl RE. Adolescent brain development: a period of vulnerabilities and opportunities. Keynote address. Ann N Y Acad Sci. 2004;1021:1-22.

2. Crews F, He J, Hodge C. Adolescent cortical development: a critical period of vulnerability for addiction. Pharmacol Biochem Behav. 2007;86:189-99.

3. Spear LP. Adolescent brain development and animal models. Ann N Y Acad Sci. 2004;1021:23-6.

4. Crews FT, Mdzinarishvili A, Kim D, He J, Nixon K. Neurogenesis in adolescent brain is potently inhibited by ethanol. Neuroscience. 2006;137:437-45.

5. Spear LP, Varlinskaya EI. Adolescence. In: Galanter M, Lowman C, Boyd GM, Faden VB, Witt E, Lagressa D, editors. Recent developments in alcoholism.Volume 17. New York: Kluwer Academic Publishers; 2005. p. 143-59.

6. Crews FT, Nixon K. Mechanisms of neurodegeneration and regeneration in alcoholism. Alcohol Alcohol. 2009;44:115-27.

7. Brown SA, Tapert SF. Adolescence and the trajectory of alcohol use: basic to clinical studies. Ann N Y Acad Sci. 2004;1021:234-44.

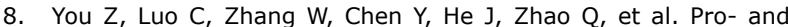
anti-inflammatory cytokines expression in rat's brain and spleen exposed to chronic mild stress: involvement in depression. Behav Brain Res. 2011;225:135-41.

9. Rettori V, Fernandez-Solari J, Prestifilippo JP, Mohn C, De Laurentiis A, Bornstein SR, et al. Endocannabinoids in TNF-alpha and ethanol actions. Neuroimmunomodulation. 2007;14:188-92.

10. Moore KW, O'Garra A, de Waal Malefyt R, Vieira P, Mosmann TR. Interleukin-10. Annu Rev Immunol. 1993;11:165-90.

11. Vitkovic L, Konsman JP, Bockaert J, Dantzer R, Homburger V, Jacque $C$. Cytokine signals propagate through the brain. Mol Psychiatry. 2000;5:604-15.

12. Collins MA, Neafsey EJ. Neuroinflammatory pathways in binge alcohol-induced neuronal degeneration: oxidative stress cascade involving aquaporin, brain edema, and phospholipase A2 activation. Neurotox Res. 2012;21:70-8.

13. Maggs JL, Schulenberg JE. Initiation and course of alcohol consumption among adolescents and young adults. In: Galanter M, Lowman C, Boyd GM, Faden VB, Witt E, Lagressa D, editors. Recent developments in alcoholism. Volume 17. New York: Kluwer Academic Publishers; 2005. p. 29-47.

14. Perry $\mathrm{CL}$, Williams CL, Komro KA, Veblen-Mortenson S, Forster $\mathrm{JL}$, Bernstein-Lachter $\mathrm{R}$, et al. Project Northland high schoo interventions: community action to reduce adolescent alcohol use. Health Educ Behav. 2000;27:29-49.

15. Pascual M, Blanco AM, Cauli O, Miñarro J, Guerri C. Intermittent ethanol exposure induces inflammatory brain damage and causes long-term behavioural alterations in adolescent rats. Eur J Neurosci. 2007;25:541-50.

16. Cruz AP, Frei F, Graeff FG. Ethopharmacological analysis of rat behavior on the elevated plus-maze. Pharmacol Biochem Behav. 1994;49:171-6.

17. Johnston $A L$, File SE. Sex differences in animal tests of anxiety. Physiol Behav. 1991;49:245-50.

18. Walf $A A$, Frye CA. The use of the elevated plus maze as an assay of anxiety-related behavior in rodents. Nat Protoc. 2007;2:322-8.

19. Toledo-Rodriguez M, Sandi C. Stress during adolescence increases novelty seeking and risk-taking behavior in male and female rats. Front Behav Neurosci. 2011;5:17.

20. Robert G, Drapier D, Bentué-Ferrer D, Renault A, Reymann JM. Acute and chronic anxiogenic-like response to fluoxetine in rats in the elevated plus-maze: modulation by stressful handling. Behav Brain Res. 2011;220:344-8.

21. Miczek KA. A new test for aggression in rats without aversive stimulation: Differential effects of d-amphetamine and cocaine. Psychopharmacology (Berl). 1979;60:253-9.

22. Bradford MM. A rapid and sensitive method for the quantitation of microgram quantities of protein utilizing the principle of proteindye binding. Anal Biochem. 1976;72:248-54.

23. de Almeida RM, Benini Q, Betat JS, Hipólide DC, Miczek KA Svensson AI. Heightened aggression after chronic flunitrazepam in male rats: potential links to cortical and caudate-putamenbinding sites. Psychopharmacology (Berl). 2008;197:309-18.

24. Spanagel R, Noori HR, Heilig M. Stress and alcohol interactions: animal studies and clinical significance. Trends Neurosci. 2014;37:219-27.

25. Walker BM, Ehlers CL. Age-related differences in the blood alcohol levels of Wistar rats. Pharmacol Biochem Behav. 2009;91:560-5.

26. Casey BJ, Jones RM. Neurobiology of the adolescent brain and behavior: implications for substance use disorders. J Am Acad Child Adolesc Psychiatry. 2010;49:1189-201.

27. McBride WJ, Bell RL, Rodd ZA, Strother WN, Murphy JM. Adolescent alcohol drinking and its long-range consequences. In: Galanter M, Lowman C, Boyd GM, Faden VB, Witt E, Lagressa $D$, editors. Recent developments in alcoholism.Volume 17. New York: Kluwer Academic Publishers; 2005; p. 123-42.

28. Kane CJ, Phelan KD, Douglas JC, Wagoner G, Johnson JW, Xu J, et al. Effects of ethanol on immune response in the brain: regionspecific changes in aged mice. J Neuroinflammation. 2013;10:66.

29. Jerrells TR, Weinberg J. Influence of ethanol consumption on immune competence of adult animals exposed to ethanol in utero. Alcohol Clin Exp Res. 1998;22:391-400.

30. Davis MI. Ethanol-BDNF interactions: still more questions than answers. Pharmacol Ther. 2008;118:36-57.

31. Moonat S, Starkman BG, Sakharkar A, Pandey SC. Neuroscience of alcoholism: molecular and cellular mechanisms. Cell Mol Life Sci. 2010;67:73-88.

32. MacLennan AJ, Leea N, Walker DW. Chronic ethanol administration decreases brain-derived neurotrophic factor gene expression in the rat hippocampus. Neurosci Lett. 1995;197:105-8.

33. Cook RT. Alcohol abuse, alcoholism, and damage to the immune system-a review. Alcohol Clin Exp Res. 1998;22:1927-42.

34. Witt ED. Research on alcohol and adolescent brain development: opportunities and future directions. Alcohol. 2010;44:119-24.

\section{Correspondence:}

Rosa Maria Martins de Almeida

Instituto de Psicologia - Universidade Federal do Rio Grande do Sul

Rua Ramiro Barcelos, 2600, Santa Cecília

90035-003 - Porto Alegre, RS - Brazil

E-mail: rosa.almeida@ufrgs.br 